\title{
Silent Crooke's cell corticotroph adenoma of the pituitary gland presenting as delayed puberty
}

\author{
Dinesh Giri', Federico Roncaroli2,3, Ajay Sinha4, Mohammed Didi' ${ }^{4}$ and \\ Senthil Senniappan'1
}

1Department of Paediatric Endocrinology, Alder Hey Children's NHS Foundation Trust, Liverpool, UK, 2Department of Histopathology, Alder Hey Children's Hospital, Liverpool, UK, 3Division of Neuroscience, University of Manchester, Manchester, UK, and ^Department of Paediatric Neurosurgery, Alder Hey Children's Hospital, Liverpool, UK

Correspondence should be addressed to S Senniappan

Email

senthilkss@yahoo.co.uk

\section{Summary}

Corticotroph adenomas are extremely rare in children and adolescents. We present a 15-year-old boy who was investigated for delayed puberty (A1P2G1, bilateral testicular volumes of $3 \mathrm{~mL}$ each). There was no clinical or laboratory evidence suggestive of chronic illness, and the initial clinical impression was constitutional delay in puberty. Subsequently, MRI scan of the brain revealed the presence of a mixed cystic and solid pituitary lesion slightly displacing the optic chiasma. The lesion was removed by transphenoidal surgery and the biopsy confirmed the lesion to be pituitary adenoma. Furthermore, the adenoma cells also had Crooke's hyaline changes and were intensely positive for ACTH. However there was no clinical/biochemical evidence of ACTH excess. There was a spontaneous pubertal progression twelve months after the surgery (A2P4G4, with bilateral testicular volume of $8 \mathrm{~mL}$ ). Crooke's cell adenoma is an extremely rare and aggressive variant of corticotroph adenoma that can uncommonly present as a silent corticotroph adenoma in adults. We report for the first time Crooke's cell adenoma in an adolescent boy presenting with delayed puberty.

\section{Learning points:}

- Constitutional delay of growth and puberty (CDGP) is a diagnosis of exclusion; hence a systematic and careful review should be undertaken while assessing boys with delayed puberty.

- Crooke's cell adenomas are a group of corticotroph adenomas that can rarely present in childhood and adolescence with delayed puberty.

- Crooke's cell adenomas can be clinically silent but are potentially aggressive tumours that require careful monitoring.

\section{Background}

The onset of puberty is a complex and largely unknown process governed by interactions between genes and environment. The absence of signs of sexual maturation in boys (testicular enlargement $\geq 4 \mathrm{~mL}$ ) by 14 years and in girls (breast bud development) by 13 years, which is 2-2.5 s.D. less than the mean population is usually referred to as delayed puberty (1). Constitutional delay of growth and puberty (CDGP) accounts for the commonest cause of delayed puberty in both genders and it is twice as frequent in boys when compared to girls (2). The other causes of delayed puberty include chronic illnesses, hypogonadotropic hypogonadism $(\mathrm{HH})$ 
(Kallman's syndrome and hypopituitarism) and hypergonadotropic hypogonadism (Turner's syndrome, Klinefelter and gonadal toxicity).

Distinguishing CDGP from other causes of $\mathrm{HH}$ can be challenging. Careful clinical observation over time is essential as progressive pubertal development can happen in CDGP. The occurrence of progressive pubertal development by 18 years of age is the 'gold standard' for differentiating CDGP from $\mathrm{HH}$ (3).

Pituitary adenomas are extremely rare in childhood and adolescence with a reported prevalence of 0.1 per million children (4). They constitute less than $3 \%$ of supratentorial tumours and $2.3-6 \%$ of all sellar tumours treated surgically (5). A retrospective review of adenomas diagnosed in adulthood suggested that symptoms often manifest during adolescence and that the prevalence of adenomas in children and adolescents may therefore be higher than reported (5).

We report a teenage boy, presenting with delayed puberty, who was initially managed for constitutional pubertal delay but subsequent investigations led to the diagnosis of an extremely rare and clinically nonfunctioning (silent) Crooke's cell corticotroph adenoma. Crooke's cell adenoma, presenting as delayed puberty in children and adolescents, has not been reported in literature before.

\section{Case presentation}

A 15-year-old boy (height: -1.6 SDS, weight-1.0 SDS, midparental height: 0.1 SDS) was referred for endocrinology consultation with concerns of delayed puberty. He had a Tanner pubertal staging of A1P2G1 and bilateral testicular volumes of $3 \mathrm{~mL}$ each. There was no history suggestive of chronic illnesses. His mother had attained menarche at 15 years of age and father was noted to be a late developer. There was no history of anosmia, headache and vomiting or visual disturbances. There were no features of hypothyroidism or cortisol excess.

\section{Investigations}

The baseline laboratory investigations did not show any biochemical evidence of chronic illness. He had a bone age delay of 2 years. The thyroid function test, serum IGF1, prolactin, 09:00h cortisol and ACTH were all within the normal limits (Table 1 ). The cortisol response (peak: $505 \mathrm{nmol} / \mathrm{L}$ at $60 \mathrm{~min}$ ) to synacthen was adequate. The baseline $\mathrm{LH}$ was $0.8 \mathrm{IU} / \mathrm{L}, \mathrm{FSH}$ was $1.4 \mathrm{IU} / \mathrm{L}$ and the morning testosterone was $0.8 \mathrm{nmol} / \mathrm{L}$. The initial clinical
Table 1 Baseline endocrine investigations.

\begin{tabular}{|c|c|}
\hline Investigations & Values \\
\hline \multicolumn{2}{|l|}{ Thyroid function test } \\
\hline FT4 & $11.8 \mathrm{pmol} / \mathrm{L}$ \\
\hline TSH & $2.85 \mathrm{pmol} / \mathrm{L}$ \\
\hline Prolactin & $100 \mu / L($ normal $<500)$ \\
\hline IGF1 & $\begin{array}{l}43 \mathrm{nmol} / \mathrm{L} \text { (normal: } \\
24-102 \text { ) }\end{array}$ \\
\hline Cortisol (09:00h) & $300 \mathrm{nmol} / \mathrm{L}$ \\
\hline АСТН (09:00 h) & $4 \mathrm{pmol} / \mathrm{L}$ (normal: $2-11)$ \\
\hline \multicolumn{2}{|l|}{ Synacthen test } \\
\hline Peak cortisol response & $505 \mathrm{nmol} / \mathrm{L}$ at $60 \mathrm{~min}$ \\
\hline $\mathrm{LH}$ & $0.8 \mathrm{IU} / \mathrm{L}$ \\
\hline FSH & $1.4 \mathrm{IU} / \mathrm{L}$ \\
\hline Testosterone & $0.8 \mathrm{nmol} / \mathrm{L}$ \\
\hline
\end{tabular}

impression was that of CDGP. The patient was closely monitored in the clinic. At 16 years, he still did not have any further progression towards puberty. An MRI scan of the brain showed a solid and cystic pituitary lesion $(2 \times 1.5 \times 1.7 \mathrm{~cm})$, which was slightly displacing the optic chiasma consistent with an adenoma (Fig. 1A and B). A detailed ophthalmology examination did not reveal any abnormality of vision. Genetic analysis of the MEN1 and AIP did not reveal any pathogenic mutation.
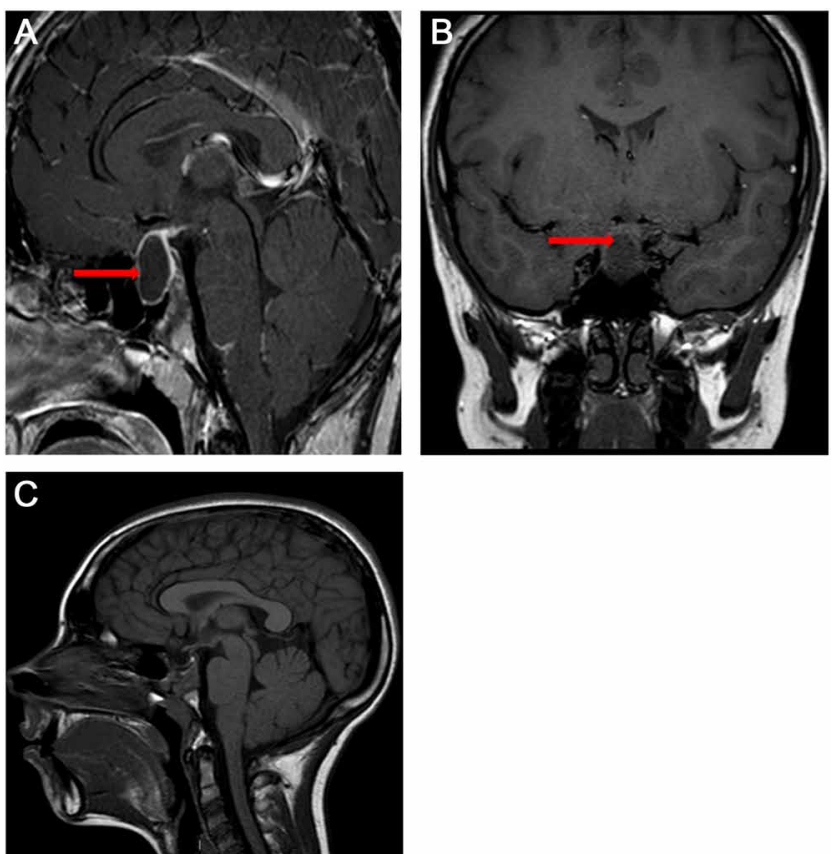

Figure 1

MRI pituitary with contrast revealing a cystic lesion in the pituitary fossa $(2 \times 1.5 \times 1.7 \mathrm{~cm})$ slightly displacing the optic chiasma (red arrow). The pituitary gland itself or the posterior pituitary cannot be separated from the mass lesion ( $A$, sagittal post-contrast, $T 1$-weigthed image; $B$, coronal view showing mixed solid and cystic leison); postoperative MRI showing stable postsurgical changes noted within the sella with no evidence of recurrence of tumour (C, sagittal post-contrast, T1-weigthed image). 


\section{Treatment}

The pituitary lesion was removed by transphenoidal surgery and no evidence of calcification in the mass was noted. Post-operatively, the recovery was good without development of any new endocrine abnormality. The post-operative MRI, 6 months after the neurosurgery, was noted to be stable (Fig. 1C) and there was commencement of puberty, A2P3G2 with bilateral $5 \mathrm{~mL}$ testes.

\section{Histopathology}

The tumour specimen contained normal adenohypophysis; fragments of a cyst walls lying adjacent to the normal anterior pituitary; and fragments of an adenoma with irregular, infiltrative margin into the adjacent gland. Immuno-histochemical stains were performed with antibodies directed against pituitary hormones, cytokeratin CAM5.2, Ki-67 and p53. The lesion was composed of acini, lobules, ribbons and trabeculae. The cytoplasm of neoplastic cells showed a perinuclear, pink, hyaline ring indicative of Crooke's hyaline changes (Fig. 2A and B). The adenoma cells were intensely and diffusely positive for ACTH (Fig. 2C). The immunostaining for cytokeratin CAM 5.2 highlighted perivascular cytokeratin deposits in the neoplastic cells that were typical of Crooke's hyaline changes, but not in the normal corticotrophes (Fig. 2D). Immunostaining for

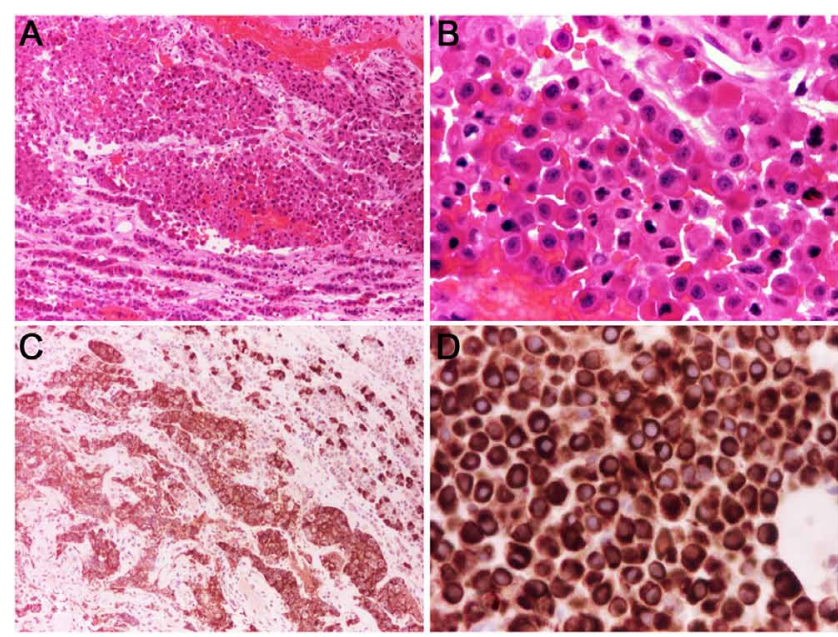

Figure 2

Tissue fragments contain a pituitary adenoma and compressed normal adenohypophysis ( $A$, haematoxylin-eosin- $\times 10$ ); neoplastic cells are uniform, show a peripheral rim of basophilic cytoplasm and perinuclear hyalinisation ( $B$, haematoxylin-eosin $-\times 40)$; the adenoma shows ubiquitous expression of $\mathrm{ACTH}(\mathrm{C}, \mathrm{ACTH}$ immunoperoxidase $-\times 10$ ); perinuclear hyaline changes consist of cytokeratin filaments ( $D, C A M 5.2$ immunoperoxidase $-\times 40$ ).

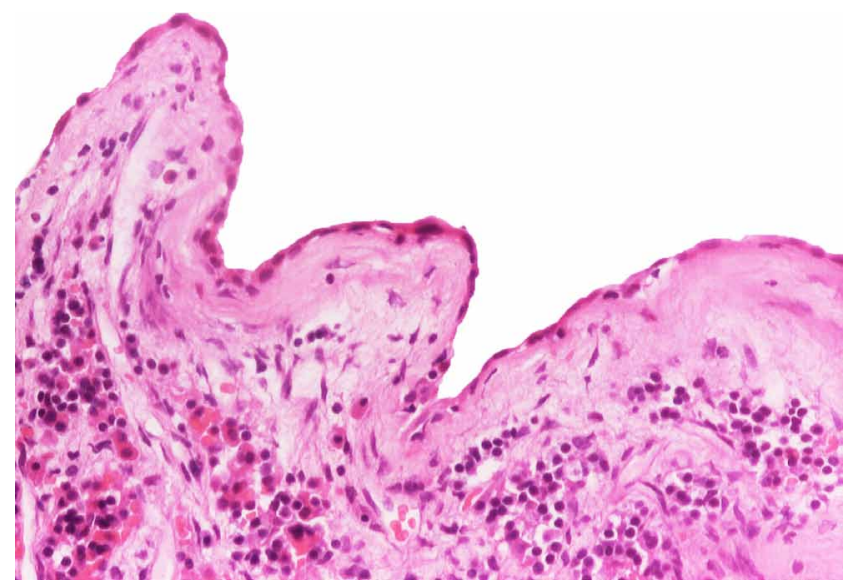

Figure 3

A cyst wall lined by flat and cuboidal epithelium on a thick basement membrane is adjacent to the normal adenohypophysis.

the other pituitary hormones were positive in the normal gland but were negative in the adenoma. About $2 \%$ of the neoplastic cells were positive for Ki-67; there was no overexpression of p53. The adenoma was adjacent to a cyst wall lined by single layer of flat and cuboidal cells on a thick basement membrane. No ciliated or mucinous cells were identified (Fig. 3).

\section{Outcome and follow-up}

A further review after 6 months revealed a spontaneous pubertal progression (A2P4G4) with bilateral testicular volume of $8 \mathrm{~mL}$. The plasma testosterone concentration was $10 \mathrm{nmol} / \mathrm{L}$ and $\mathrm{GnRH}$ test suggested a pubertal response (peak LH: $24.4 \mathrm{IU} / \mathrm{L}$ and FSH: $18 \mathrm{IU} / \mathrm{L}$ ) suggesting a good recovery of hypothalamo-pituitarygonadal axis post-surgery. There were no clinical signs of cortisol excess. An overnight dexamethasone suppression test ( $1 \mathrm{mg}$ of oral dexamethasone at 23:00 h) supressed the $09: 00 \mathrm{~h}$ cortisol to $<50 \mathrm{nmol} / \mathrm{L}$ ruling out biochemical hypercortisolism.

\section{Discussion}

We report a teenager who presented with delayed puberty, which led to the initial clinical impression of constitutional delay: the most common cause of delayed puberty in boys. However further investigations established a diagnosis of pituitary adenoma, which was histologically proven to be a Crooke's cell adenoma (CCA).

Silent corticotroph pituitary adenomas (SCAs) are a rare form of pituitary adenomas that show positive staining for ACTH in immunohistochemical studies, but not 
associated with perioperative clinical or laboratory features of hypercortisolaemia (6). SCAs are very rarely diagnosed in childhood and adolescence and they represent an uncommon cause of arrest in the pubertal development (7). The most frequently reported presenting features of SCAs are tumour mass effects, including headaches, visual disturbance and hypopituitarism (8). Our patient did not have features suggestive of raised intracranial pressure; however he had features of pituitary involvement in the form of hypogonadotropic hypogonadism.

Histologically, the lesion showed ACTH expression although the patient had no clinical evidence of cortisol excess. SCAs are usually biochemically silent but some SCAs have been reported to have elevated ACTH levels with normal cortisol levels (8). The lack of signs and symptoms of hypercortisolim in patients with SCA may be related to dysregulated POMC processing leading to insufficient or bio-inactive ACTH molecules (9). SCAs can be more aggressive than the other clinically non-functioning adenomas with a higher prevalence of cavernous sinus invasion and a higher rate of recurrences (10).

Histologically, the tumour in our case had the features of CCA. CCA is an uncommon and under-investigated subtype of corticotroph adenoma accounting for less than $1 \%$ of the pituitary adenomas and $4 \%$ of the corticotropinomas (11). CCA is reportedly an aggressive variant of corticotroph adenoma (11). An extensive review of 80 cases published in the English literature showed that CCAs are more common in females $(74.6 \%)$ and have a mean age occurrence of 42.4 years (12). They usually present as macroadenomas (77.2\%) frequently extending to the cavernous sinus or invading the sellar bone (13). CCAs are rarely silent. Silent CCAs can occasionally change into a functioning adenoma, especially upon recurrence (13). Diagnosis is only made on histopathological examination when Crooke's hyaline changes are present in more than $50 \%$ of the neoplastic cells.

The adenoma in our patient was also associated with a cyst consistent with Rathke's cleft cyst (RCC). The coexistence of adenoma and RCC is now known not to be as rare as thought previously $(14,15)$. Small, asymptomatic RCCs concomitant to adenoma are more frequent and are usually found as incidental post-mortem finding and the commonest association was with prolactinoma and the least frequent was ACTH-secreting adenomas (16). Our patient had an initial clinical course suggestive of CDGP, but was subsequently identified to have a CCA that is currently biochemically and clinically silent.

\section{Conclusion}

CCA is an uncommon form of corticotroph adenomas, which is usually associated with an aggressive clinical course. Rarely, as in our case, CCAs can be clinically silent but require careful monitoring to identify the possible change to Cushing's disease, and post-operative recurrences. The case also highlights the well-established fact that systematic and careful review is important while assessing boys with delayed puberty, as CDGP should be a diagnosis of exclusion.

Declaration of interest

The authors declare that there is no conflict of interest that could be perceived as prejudicing the impartiality of the research reported.

\section{Funding}

This research did not receive any specific grant from any funding agency in the public, commercial or not-for-profit sector.

\section{Patient consent}

A written informed consent has been obtained from the patient's parent for publication of the submitted article and accompanying images.

\section{Author contribution statement}

D Giri wrote the manuscript draft. F Roncaroli helped with the histology section and manuscript revision. M Didi and A Sinha helped with the revision of the manuscript. S Senniappan is the lead clinician for the patient and supervised the manuscript writing and helped with further revision. All authors read and approved the final draft of the manuscript.

\section{References}

1 Marshall WA \& Tanner JM 1970 Variations in the pattern of pubertal changes in boys. Archives of Disease in Childhood 45 13-23. (doi:10.1136/adc.45.239.13)

2 Soliman AT \& De Sanctis V 2012 An approach to constitutional delay of growth and puberty. Indian Journal of Endocrinology and Metabolism 16 698-705. (doi:10.4103/2230-8210.100650)

3 Harrington J \& Palmert MR 2012 Distinguishing constitutional delay of growth and puberty from isolated hypogonadotropic hypogonadism: critical appraisal of available diagnostic tests. Journal of Clinical Endocrinology and Metabolism 97 3056-3067. (doi:10.1210/ jc.2012-1598)

4 Mindermann T \& Wilson CB 1995 Pediatric pituitary adenomas. Neurosurgery 36 259-269. (doi:10.1227/00006123-199502000-00004)

5 Cannavò S, Venturino M, Curtò L, De Menis E, D'Arrigo C, Tita P, Billeci D \& Trimarchi F 2003 Clinical presentation and outcome of pituitary adenomas in teenagers. Clinical Endocrinology 58 519-527. (doi:10.1046/j.1365-2265.2003.01748.x)

6 Cooper O 2015 Silent corticotroph adenomas. Pituitary 18 225-231. (doi:10.1007/s11102-014-0624-3)

7 Singh SK \& Aggarwal R 2005 Pituitary adenomas in childhood. Indian Journal of Pediatrics 72 583-591. (doi:10.1007/BF02724183) 
8 Scheithauer BW, Jaap AJ, Horvath E, Kovacs K, Lloyd RV, Meyer FB, Laws ER Jr \& Young WF Jr 2000 Clinically silent corticotroph tumors of the pituitary gland. Neurosurgery $\mathbf{4 7}$ 723-729; discussion 729-730. (doi:10.1097/00006123-20000900000039)

9 Ohta S, Nishizawa S, Oki Y, Yokoyama T \& Namba H 2002 Significance of absent prohormone convertase $1 / 3$ in inducing clinically silent corticotroph pituitary adenoma of subtype I: immunohistochemical study. Pituitary 5 221-223. (doi:10.1023/ A:1025321731790)

10 Jahangiri A, Wagner JR, Pekmezci M, Hiniker A, Chang EF, Kunwar S, Blevins L \& Aghi MK 2013 A comprehensive longterm retrospective analysis of silent corticotrophic adenomas vs hormonenegative adenomas. Neurosurgery 73 8-17. (doi:10.1227/01. neu.0000429858.96652.1e)

11 George DH, Scheithauer BW, Kovacs K, Horvath E, Young WF Jr, Lloyd RV \& Meyer FB 2003 Crooke's cell adenoma of the pituitary: an aggressive variant of corticotroph adenoma. American Journal of
Surgical Pathology 27 1330-1336. (doi:10.1097/00000478-20031000000005)

12 Di Ieva A, Davidson JM, Syro LV, Rotondo F, Montoya JF, Horvath E, Cusimano MD \& Kovacs K 2015 Crooke's cell tumors of the pituitary. Neurosurgery 76 616-622. (doi:10.1227/NEU.0000000000000657)

13 Holthouse DJ, Robbins PD, Kahler R, Knuckey N \& Pullan P 2001 Corticotroph pituitary carcinoma: case report and literature review. Endocrine Pathology 12 329-341. (doi:10.1385/EP:12:3:329)

14 Ikeda H \& Ohhashi G 2015 Demonstration of high coincidence of pituitary adenoma in patients with ruptured Rathke's cleft cyst: results of a prospective study. Clinical Neurology and Neurosurgery 139 144-151. (doi:10.1016/j.clineuro.2015.09.018)

15 Sumida M, Migita K, Tominaga A, Iida K \& Kurisu K 2001 Concomitant pituitary adenoma and Rathke's cleft cyst. Neuroradiology 43 755-759. (doi:10.1007/s002340100559)

16 Noh SJ, Ahn JY, Lee KS \& Kim SH 2007 Pituitary adenoma and concomitant Rathke's cleft cyst. Acta Neurochirurgica 149 1223-1228. (doi:10.1007/s00701-007-1295-x)

Received in final form 28 January 2017

Accepted 24 February 2017 